\title{
Performance Evaluation of a VLC Transmitter Based on the Split of the Power
}

\author{
Juan Rodríguez, Daniel G. Aller, Diego G. Lamar, and Javier Sebastián. \\ Electronic Power Supply Systems Group \\ University of Oviedo \\ Campus de Viesques, s/n, 33204, Gijón, Spain. \\ rodriguezmjuan@uniovi.es
}

\begin{abstract}
Visible Light Communication (VLC) has gained relevance during last years. It consists in using High-Brightness LEDs (HB-LEDs) both for lighting and for transmitting information changing the light intensity rapidly. However, there are some bottlenecks that are slowing down the deployment of this technology. One of the most important problems is that the HBLED drivers proposed for addressing high data rates in VLC achieve poor power efficiency. Since these HB-LED drivers must be able to reproduce fast current waveforms, the use of Linear Power Amplifiers (LPAs) has been adopted, which clearly damage the power efficiency of HB-LED lighting. In order to alleviate this problem, a HB-LED driver made up of two DC-DC power converters is presented in this work. One of them is responsible for performing the communication functionality by operating at high switching frequency $(10 \mathrm{MHz})$, whereas the second one fulfills the illumination functionality by ensuring a certain biasing point. The split of the power allows to minimize the power delivered by the fast-response DC-DC power converter. Thus, the efficiency can be maximized for scenarios with changing conditions (i.e., mobile transmitter and/or receiver, presence of mobile obstacles, etc.). In this sense, how the lighting level and the communication signal power affect both the power efficiency and the communication efficiency is deeply analyzed. The implemented prototype achieves an overall efficiency around $90 \%$. In addition, the proposed VLC transmitter is able to reproduce a wide range of digital modulation schemes, including Orthogonal Frequency Division Multiplexing (OFDM).
\end{abstract}

Keywords - High switching frequency, Orthogonal Frequency Division Multiplexing (OFDM), Visible Light Communication (VLC), High-Brightness LED (HB-LED), output-series connection.

\section{INTRODUCTION}

Wireless communication is essential for the present and future society. A lot of emerging topics, such as the smart city concept or the development of the smartphones technology, promote the communication between humans and many devices placed into the environment. As a result, the mobile data traffic has grown exponentially during last decade and it is expected that it keeps growing by 2021 [1]. However, enabling the predicted data traffic is not straightforward because the Radio Frequency (RF) spectrum is close to congestion.

Visible Light Communication (VLC) is one of the most promising solutions for alleviating the problem [2]-[5]. It consists in using the High-Brightness LEDs (HB-LEDs) not only for lighting, but also for transmitting information. In this application, the light intensity has a DC component that determines the lighting level and an AC component that represents the transmitted information. Obviously, the light intensity modulation is fast enough to be unappreciable to the human eye.

In general, a blue Gallium Nitride (GaN) HB-LED in combination with a yellow inorganic phosphor is the preferred approach for obtaining white light in Solid-State Lighting (SSL). However, this phosphor limits the HB-LED bandwidth to a few $\mathrm{MHz}$ (3-5 MHz) [6]-[7]. Several strategies have been proposed to overcome this limitation. For instance, RGB HB-LEDs can be used to achieve a bandwidth around $10-20 \mathrm{MHz}$ per color [8] In any case, a fast HB-LED driver able to reproduce current waveforms of several $\mathrm{MHz}$ is mandatory.

Regardless the particular bandwidth provided by the light source, maximizing the data rate for this bandwidth is a main target. It is important to note that the data rate depends on the modulation scheme. Two main approaches can be found in the literature. The first one consists in generating light pulses for transmitting the information [9]-[10] [see Fig. 1(a)]. This method is simple and it can be implemented with a power efficient HB-LED driver. As Fig. 2 shows, an extra MOSFET in series or in parallel with the HB-LED string can be used to implement the method. The main drawback is that pulse-based modulation schemes are inefficient from the communication perspective, which implies that they cannot achieve high bit rates when the available bandwidth is as limited as in the case of HB-LEDs.

The second approach is based on reproducing advanced modulation schemes that provide a higher data rate than pulsebased modulation schemes for the same bandwidth [see Fig.

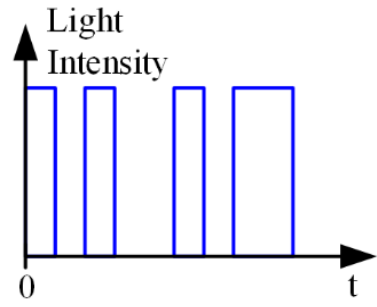

(a)

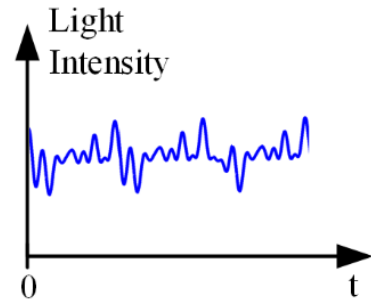

(b)
Fig. 1. Example of light intensity waveforms in VLC: (a) Pulse-based modulation scheme. (b) Advanced modulation scheme. 
1(b)]. The drawback is that this method jeopardizes the main advantage of HB-LED lighting: the power efficiency. The reason is that the HB-LED drivers that have been proposed for reproducing this kind of modulation schemes use a Linear Power Amplifier (LPA) for delivering the AC component while a DCDC power converter determines the DC component. It is important to note that a class A or B LPA barely achieves a power efficiency above $40 \%$. As a conclusion, reproducing advanced modulation schemes is mandatory for enabling the massive data traffic predicted for upcoming years. However, improving the HB-LED driver efficiency is an important limitation that must be overcome.

Some recent works have addressed the issue [11]-[15]. In [11], several VLC transmitters fully or partially based on the use of DC-DC power converters are proposed. However, there is a lack of technical analysis and some important issues, such as the dependence of the HB-LED behavior on the operating temperature, are not considered. In [13], a two-phase synchronous buck converter able to reproduce single-carrier digital modulation schemes by controlling its output voltage ripple is presented. Since the first switching harmonic acts as the carrier of the reproduced modulation scheme, the approach provides the highest ratio between the bit rate and the required switching frequency. The major drawback of this method is that it is not able to reproduce multi-carrier digital modulation schemes, such as Orthogonal Frequency Division Multiplexing (OFDM), which are preferable in some scenarios [16]-[19].

In the present work, a VLC transmitter able to reproduce both single-carrier and multi-carrier digital modulation schemes is proposed. The architecture is made up of two DC-DC power converters in output-series connection [15]. The first one is a fast response DC-DC converter that performs the communication functionality. The second one fulfills the illumination functionality by ensuring a certain biasing point.

The paper is organized as follows. The driving requirements for VLC and the proposed HB-LED are explained in Section II. The experimental results are given in Section III and finally, the conclusions are gathered in Section IV.

\section{PROPOSED HB-LED DRIVER}

\section{A. Driving Requierements}

The study of the relationship between the light intensity emitted by a HB-LED string $(\mathrm{s}(\mathrm{t}))$, the current through it $\left(\mathrm{i}_{\mathrm{O}}(\mathrm{t})\right)$ and the applied voltage $\left(\mathrm{vo}_{\mathrm{O}}(\mathrm{t})\right)$ is essential for designing the HBLED driver. The behavior depends on the particular HB-LED that is used, but certain general characteristics can be identified [20]-[22]. It can be assumed that the light intensity is proportional to the current. Regarding the current versus voltage relation, it is typically modeled as an ideal diode in series with a constant voltage source (i.e., the knee voltage) and the dynamic resistance. Moreover, the impact of the HB-LED junction temperature $\left(T_{\mathrm{J}}\right)$ must be taken into account. Basically, the knee voltage $\left(V_{K}\right)$ falls with $T_{J}$ while the dynamic resistance remains

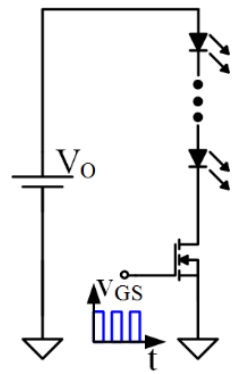

(a)

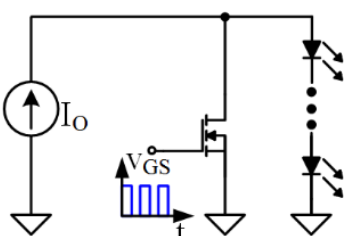

(b)
Fig. 2. HB-LED drivers for reproducing pulse-based modulation schemes: (a) MOSFET in series with the HB-LED string. (b) MOSFET in parallel with the HB-LED string.

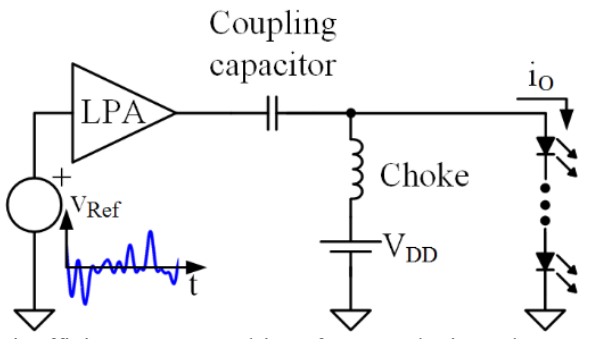

Fig. 3. Power inefficient HB-LED driver for reproducing advanced modulation schemes.

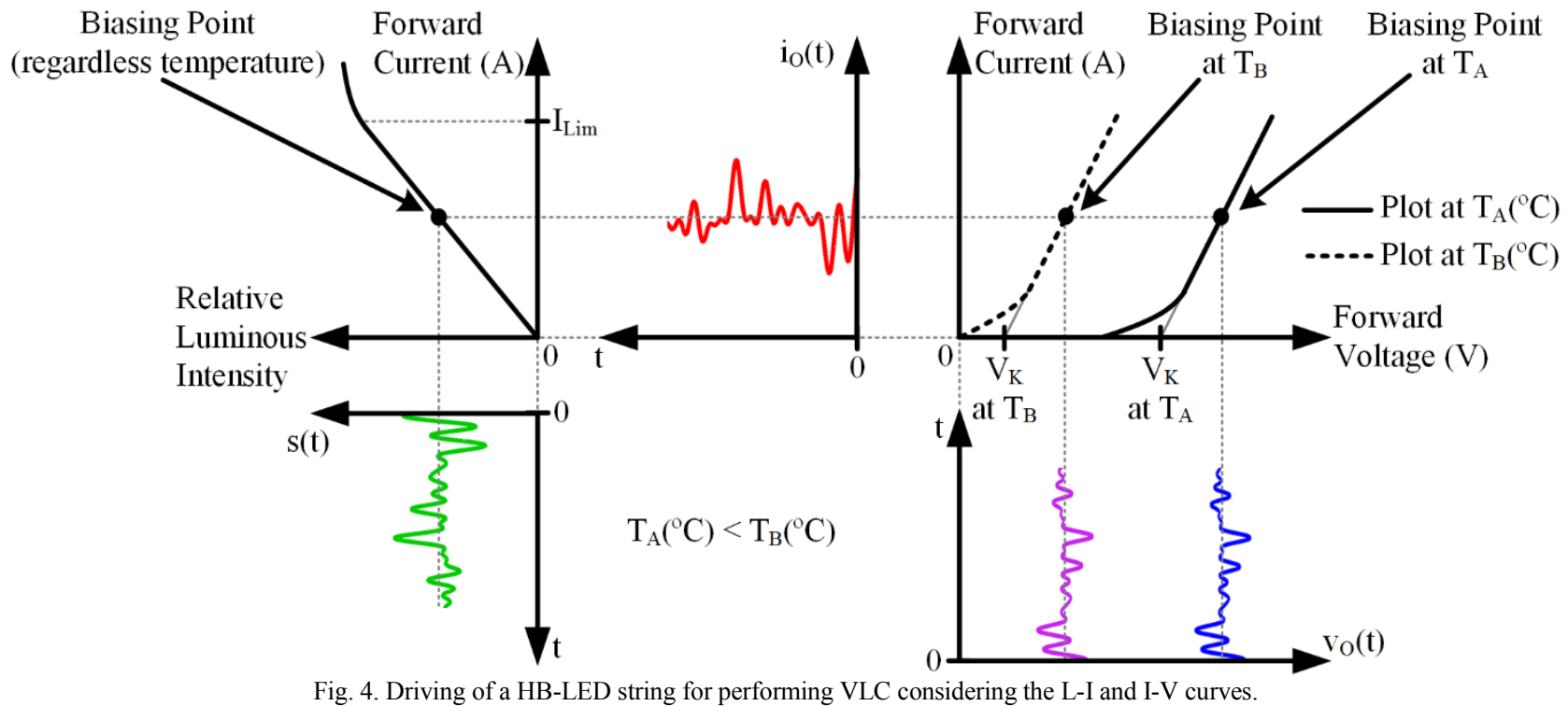


almost constant. Fig. 4 models the HB-LED behavior for two different $T_{J}$ values. The figure also shows the dependence of the voltage waveform on $T_{J}$ when reproducing a particular light intensity waveform. It can be seen that the DC component of $V_{O}(t)$ (i.e., $V_{O}-D C$ ) depends on $T_{J}$ because of the change of $V_{K}$. However, since the dynamic resistance does not depend on $T_{\mathrm{J}}$, the $\mathrm{AC}$ component of $\mathrm{vo}_{\mathrm{O}}(\mathrm{t})$ (i.e., $\mathrm{V}_{\mathrm{O}-\mathrm{AC}}(\mathrm{t})$ ) does not change. As a conclusion, a current loop is mandatory when a DC-DC converter is used for driving HB-LEDs. However, controlling the average current (i.e., $i_{\text {O-DC }}(\mathrm{t})$ ) instead of the whole current waveform is enough for ensuring the desired operation. Thus, the feedback loop of the HB-LED driver does not limit the speed of the HB-LED driver for reproducing the AC component of the current through the HB-LED string (i.e., io-AC $(\mathrm{t}))$.

\section{B. Proposed Architecture}

Fig. 5 shows the proposed HB-LED driver. It is made up of two DC-DC power converters in output-series connection. The low-side converter is a synchronous buck converter that operates in close-loop by controlling io-DC $(t)$. In the case of the high-side converter, a P-phase buck converter with high order output filter operates in open-loop performing the small voltage variations. The multi-phase buck topology [23] was conceived to be used as Voltage Regulator Modules (VRMs) for supplying microprocessors due to the high efficiency and high bandwidth achieved [24]-[25]. In addition, this topology is widely used as envelope amplifier when applying the envelope tracking (ET) technique [26]-[34]. These applications have some similarities with the high-side converter of the proposed VLC transmitter architecture: the output voltage level is low, the demanding bandwidth is very high, very low output voltage ripple is mandatory and in the case of both ET and VLC, a certain voltage reference must be tracked. In addition, a $\mathrm{M}^{\text {th }}$ order low-pass filter is considered at the output of P-phase buck converter. The use of a fourth or higher order output filter was already proposed in ET for reducing the output voltage ripple [31]-[38]. In the proposed HB-LED driver, the output voltage of the multi-phase buck converter $\left(\mathrm{v}_{\mathrm{O}-\mathrm{H}}(\mathrm{t})\right)$ is the sum of $\mathrm{V}_{\mathrm{O}-\mathrm{AC}}(\mathrm{t})$ plus a particular DC voltage (vo-H-DC). In this way, the synchronous buck converter adds the remaining DC voltage ( $\left.\mathrm{vo}_{\mathrm{L}-\mathrm{L}}(\mathrm{t})\right)$ that is needed for achieving the desired lighting level.

In order to ensure enough output voltage ripple rejection without demanding an unaffordable filter order, the switching frequency of the multi-phase buck converter $\left(\mathrm{f}_{\mathrm{SW}-\mathrm{H}}\right)$ must be at least between 3 and 6 times higher than the maximum frequency of the communication signal that is going to be reproduced. In practice, it implies a switching frequency in the range of tens of $\mathrm{MHz}$ and, consequently, high switching losses that jeopardize the converter efficiency. Therefore, the power delivered by this converter must be as low as possible, which can be done by selecting VO-H-DC barely higher than the one that always ensures $\mathrm{V}_{\mathrm{O}-\mathrm{H}}(\mathrm{t})>0 \mathrm{~V}$. Minimizing the power delivered by the multiphase buck converter is equivalent to maximizing the power delivered by the synchronous buck converter. In this way, the overall efficiency of the driver is maximized. It is important to note that since the synchronous buck converter only needs to track a constant current reference (io-DC-Ref), its design is similar to a conventional HB-LED driver for lighting applications and, therefore, it can achieve a very high efficiency.

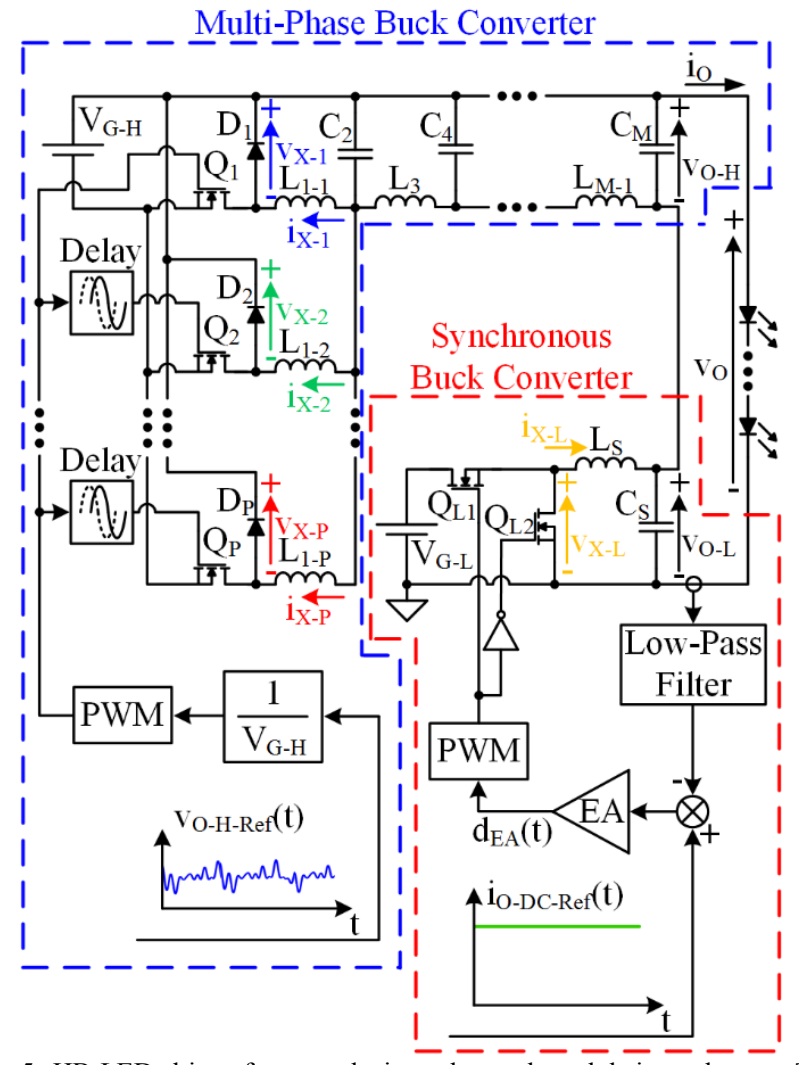

Fig. 5. HB-LED driver for reproducing advanced modulation schemes. The multi-phase buck converter performs the communication functionality while the synchronous buck converter fulfills the illumination functionality by ensuring a certain biasing point.

In summary, since the proposed HB-LED driver is fully based on the use of DC-DC converters, it can achieve higher efficiency than the circuit shown in Fig 3. Moreover, the overall efficiency of the HB-LED driver can be maximized by minimizing the power delivered by the multi-phase buck converter. In other words, the HB-LED driver operation can be dynamically adjusted to the particular requirements of the VLC application and communication scenario.

In addition, the proposed HB-LED driver has other positive points that must be highlighted. It is well know that driving floating MOSFET is difficult when the switching frequency is high. This is the case of the conventional buck converter. However, in the proposed configuration, the MOSFETs source are connected to a constant voltage point of the DC-DC converter (see Fig. 5). Thus, the MOSFETs driving task becomes easier.

Another advantage is that the output-series connection enables an accurate reproduction of $\mathrm{v}_{\mathrm{O}-\mathrm{AC}}(\mathrm{t})$ with relative ease. It is important to note that $\mathrm{v}_{\mathrm{O}-\mathrm{AC}}(\mathrm{t})$ is small in comparison to $\mathrm{v}_{\mathrm{O}-}$ DC due to the knee voltage of the HB-LEDs. As a result, reproducing the required $\mathrm{v}_{\mathrm{O}}(\mathrm{t})$ is difficult if a single DC-DC converter is used. Fortunately, the multi-phase buck converter of the proposed architecture is focused on performing the small voltage variations while the synchronous buck converter provide most of $v_{O}-D C$, thus facilitating the reproduction of $v_{O}(t)$. More details regarding the proposed HB-LED driver can be found in [15]. 
Regarding the drawbacks, the two isolated input voltages (i.e. $\mathrm{V}_{\mathrm{G}-\mathrm{H}}$ and $\mathrm{V}_{\mathrm{G}-\mathrm{L}}$ ) required for the implementation is the weakest point of the approach.

\section{EXPERIMENTAL RESULTS}

\section{A. Prototype Details}

A two-phase asynchronous buck converter with $4^{\text {th }}$ order Butterworth filter and a single-phase synchronous buck converter were built (see Fig. 6). The switching frequency of the multi-phase buck converter and the synchronous buck converter are $10 \mathrm{MHz}$ and $250 \mathrm{kHz}$, respectively. Si-MOSFETs are used in both converters: SSM3K336R in the multi-phase buck converter and TK7S10N1Z in the synchronous buck converter. The load is made up of 6 HB-LEDs (W42180 Seoul Semiconductor) connected in series. The input voltage of the multi-phase buck converter and the synchronous buck converter are $8.5 \mathrm{~V}$ and $24 \mathrm{~V}$, respectively. Regarding the communication signal, a 64-QAM-OFDM scheme is reproduced. It is important to note that the maximum frequency of the reproduced modulation scheme is around $3 \mathrm{MHz}$. The maximum bit rate achieved by this modulation scheme is $17.4 \mathrm{Mbps}$. However, some carriers of the 64-QAM-OFDM scheme must be deactivated in order to obtain an acceptable error during the demodulation. As a result, the actual bit rate is $11.4 \mathrm{Mbps}$.

\section{B. Four Points Test}

In order to deeply evaluate the behavior of the HB-LED driver prototype, it is tested under different operating conditions. The exercise target is to study how the lighting level and the communication signal power affect both the power efficiency and the communication efficiency. Obviously, the lighting level depends on the average current through the HB-LED string (i.e., $\mathrm{i}_{\mathrm{O}-\mathrm{DC}}$ ). Regarding the communication signal power, it can be controlled by adjusting the peak to peak value of $\mathrm{v}_{\mathrm{O}}(\mathrm{t})$ (i.e., $\Delta \mathrm{v}_{\mathrm{O}}$ ). It is important to note that the modulation scheme only determines the shape of the communication signal. The signal can be amplified more or less depending on the particular application requirements, but the reproduced modulation scheme is the same.

Two lighting levels (determined by io-DC $=300 \mathrm{~mA}$ and io$\mathrm{DC}=500 \mathrm{~mA}$ ) and two levels of the communication signal power (determined by $\Delta \mathrm{v}_{\mathrm{O}}=4.1 \mathrm{~V}$ and $\Delta \mathrm{v}_{\mathrm{O}}=2.2 \mathrm{~V}$ ) are considered. As a result, there are four possible situations. Fig. 7 exemplifies the performed test and facilitates the understanding of the reasoning that will appear along this section.

Fig. 8 shows the main waveforms of the VLC system for each situation. Note that $\mathrm{V}_{\mathrm{RX}}$ is the signal at the receiver (PDA10A-EC) when it is placed at $20 \mathrm{~cm}$ from the transmitter. The DC component of $\mathrm{V}_{\mathrm{RX}}$ (i.e., $\mathrm{v}_{\mathrm{RX}-\mathrm{DC}}$ ) measures the lighting level while the peak to peak value (i.e., $\Delta \mathrm{v}_{\mathrm{RX}}$ ) is determined by the communication signal power. Table I indicates both the DC component and the peak to peak value of each waveform. In addition, it shows the amount of power delivered by the multiphase buck converter $\left(\mathrm{P}_{\mathrm{O}-\mathrm{H}}\right)$ and by the synchronous buck converter $\left(\mathrm{P}_{\mathrm{O}-\mathrm{L}}\right)$, the overall efficiency $(\eta)$ and a figure-of-merit for evaluating the communication efficiency that will be introduced below.

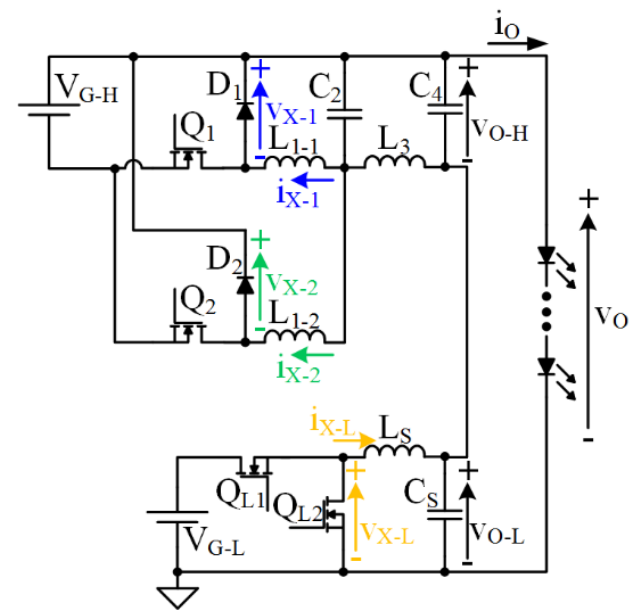

(a)

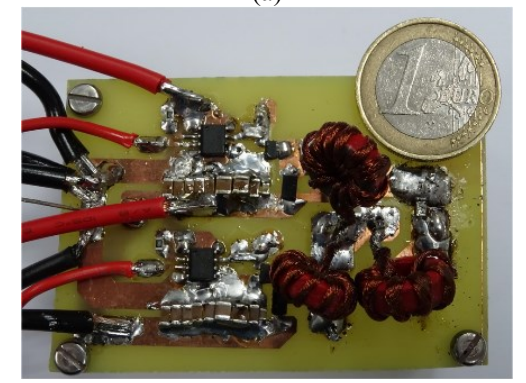

(b)

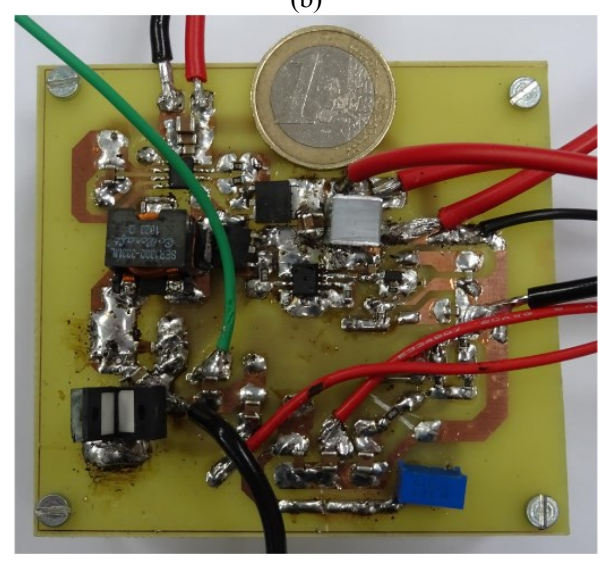

(c)

Fig. 6. Two-phase buck converter with $4^{\text {th }}$ order filter in output-series connection with a synchronous buck converter: (a) Schematic circuit of the implemented HB-LED driver. (b) Two-phase buck converter prototype. (c) Synchronous buck converter prototype.

In situation $1, \mathrm{i}_{\mathrm{O}-\mathrm{DC}}$ and $\Delta \mathrm{v}_{\mathrm{O}-\mathrm{AC}}$ are $500 \mathrm{~mA}$ and $4.1 \mathrm{~V}$, respectively. Note that as it was indicated in Section II.B, vo$\mathrm{AC}(\mathrm{t})$ is small in comparison to $\mathrm{V}_{\mathrm{O}-\mathrm{DC}}$. It can be seen that most of $\mathrm{V}_{\mathrm{O}-\mathrm{DC}}$ is delivered by the synchronous buck converter. In this situation, the power of the HB-LED driver is $10.1 \mathrm{~W}$, the $81 \%$ of the power is provided by the synchronous buck converter and the overall efficiency is $91.3 \%$.

Comparing situation 2 to situation 1 allows to study the impact of decreasing the lighting level on the power efficiency of the HB-LED driver (io-DC falls from $500 \mathrm{~mA}$ to $300 \mathrm{~mA}$ ). In order to achieve the lower biasing point, the synchronous buck converter decreases its output voltage and, as a result, the 


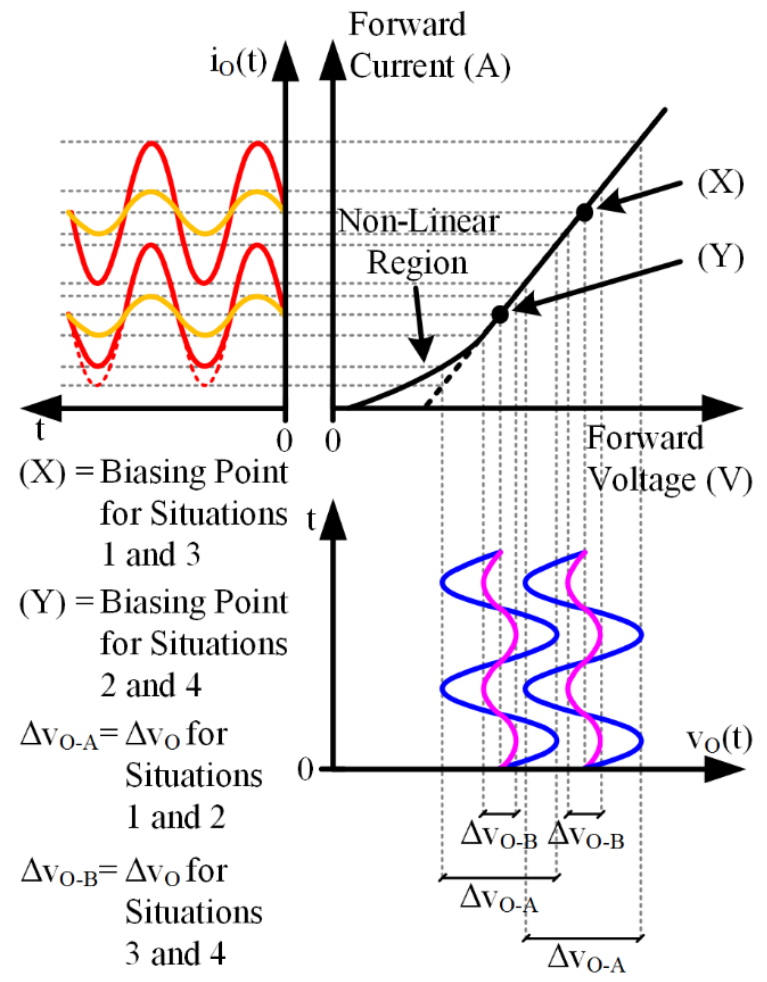

Fig. 7. Graphical description of the four point test considering the I-V curve of the HB-LED string and sinusoidal waveforms.

amount of power delivered by this converter falls. It is important to note that since the communication signal power is the same, the peak to peak values of the waveforms are the same as in situation 1. Actually, $\Delta \mathrm{i}_{\mathrm{O}}$ changes because the transmitter partially works in the non-linear region of the HB-LED string. It can be easily understood seeing Fig. 7. How this fact affects the communication will be addressed below. Another important point is that the operating conditions of the multi-phase buck converter do not change with respect to situation 1 . Taking into account all these facts, the weight of the synchronous buck efficiency on the overall efficiency is lower in situation 2 than in situation 1 and, consequently, the overall efficiency falls.

In order to study the impact of reducing the communication signal power on the power efficiency of the HB-LED driver, situation 3 can be compared to situation $1\left(\Delta \mathrm{v}_{\mathrm{O}}\right.$ falls from $4.1 \mathrm{~V}$ to $2.2 \mathrm{~V}$ ). All the peak to peak values of the waveforms change while the values of iO-DC, $_{\text {O-DC }}$ and $\mathrm{V}_{\mathrm{RX} \text {-DC }}$ are the same as in situation 1. However, it is important to note that the output voltage of the synchronous buck converter is higher in the case of situation 3. It is because the $\mathrm{AC}$ voltage provided by the

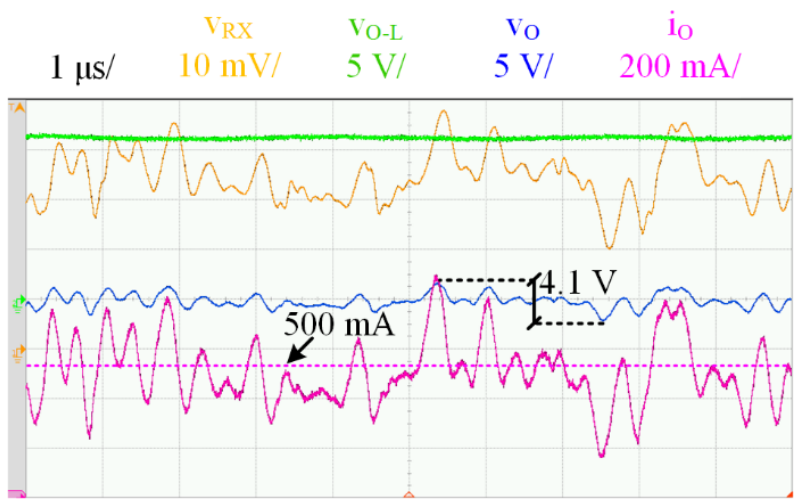

(a)

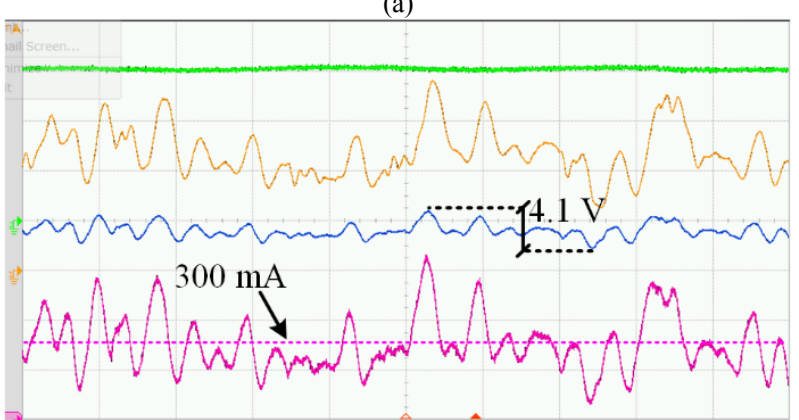

(b)

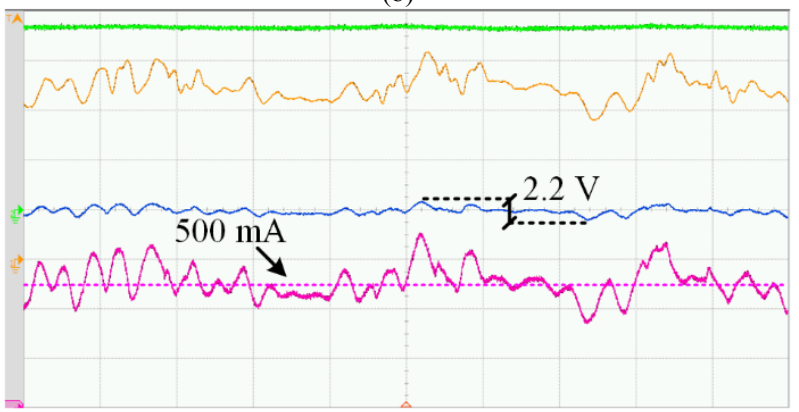

(c)

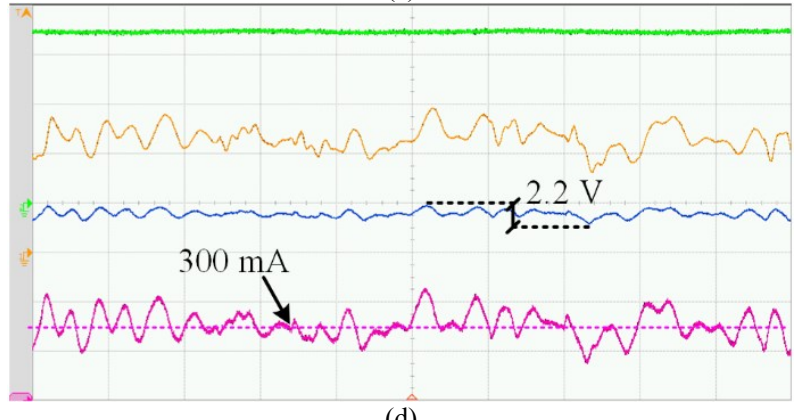

(d)

Fig. 8. Main experimental waveforms of the VLC system during the four points test: (a) Situation 1. (b) Situation 2. (c) Situation 3. (d) Situation 4.

TABLE I. MAIN PARAMETERS OF THE FOUR POINTS TEST

\begin{tabular}{|c|c|c|c|c|c|c|c|c|c|c|c|c|}
\hline & $\begin{array}{l}\mathrm{i}_{\mathrm{O}-\mathrm{DC}} \\
(\mathrm{mA})\end{array}$ & $\begin{array}{c}\Delta \mathrm{i}_{\mathrm{o}} \\
(\mathrm{mA})\end{array}$ & $\begin{array}{l}\text { Vo-DC } \\
\text { (V) }\end{array}$ & $\begin{array}{l}\Delta \mathrm{v}_{\mathrm{O}} \\
\text { (V) }\end{array}$ & $\begin{array}{l}\mathrm{V}_{\mathrm{O}-\mathrm{L}} \\
(\mathrm{V})\end{array}$ & $\begin{array}{l}\mathrm{V}_{\mathrm{RX}-\mathrm{DC}} \\
(\mathrm{mV})\end{array}$ & $\begin{array}{l}\Delta \mathrm{V}_{\mathrm{RX}} \\
(\mathrm{mV})\end{array}$ & $\begin{array}{l}\mathrm{P}_{\mathrm{O}-\mathrm{H}} \\
(\mathrm{W})\end{array}$ & $\begin{array}{l}\mathrm{P}_{\mathrm{O}-\mathrm{L}} \\
\text { (W) }\end{array}$ & $\begin{array}{c}\mathrm{P}_{\mathrm{O}} \\
(\mathrm{W})\end{array}$ & $\begin{array}{c}\eta \\
(\%)\end{array}$ & $\begin{array}{c}\mathrm{EVM}_{\mathrm{RMS}} \\
(\%)\end{array}$ \\
\hline Situation 1 & 500 & 750 & 19.9 & 4.1 & 16.1 & 34 & 29 & 8.19 & 1.24 & 10.1 & 91.3 & 22.3 \\
\hline Situation 3 & 500 & 350 & 19.9 & 2.2 & 18.2 & 34 & 15 & 9.56 & 0.52 & 10.08 & 93.6 & 23.2 \\
\hline Situation 4 & 300 & 300 & 19 & 2.2 & 17.3 & 23 & 15 & 5.31 & 0.51 & 5.82 & 91.3 & 24 \\
\hline
\end{tabular}


multi-phase buck converter is lower in this situation, so its DC voltage is reduced to minimize the power that it delivers. Consequently, the synchronous buck converter increases its output voltage for providing the desired lighting level. It can be seen that the power of the HB-LED driver is almost the same in situation 1 and in situation 3. However, the power share is different. In situation 3 , the power provided by the synchronous buck converter (94.8\% of the total power) is higher than in situation 1 and, as a result, the overall efficiency rises.

Finally, the remaining situation appears in situation 4 , where both the lighting level and the communication signal power fall (io-DC falls from $500 \mathrm{~mA}$ to $300 \mathrm{~mA}$ and $\Delta \mathrm{v}_{\mathrm{O}}$ falls from $4.1 \mathrm{~V}$ to $2.2 \mathrm{~V}$ ). In this situation, the power of the HB-LED driver is 5.82 $\mathrm{W}$, the synchronous buck converter delivers the $91.2 \%$ of the total power and the overall efficiency is $91.3 \%$.

In summary, minimizing the communication signal power and maximizing the lighting level is the best strategy for achieving the highest power efficiency. However, the impact of both the lighting level and the communication signal power on the communication efficiency must also be taken into account. Basically, the communication efficiency depends on two parameters: the distortion and the power of the received signal. In general, the higher the power of the received signal, the higher the communication efficiency because the signal can be demodulated easier. Obviously, the higher the signal distortion, the lower the communication efficiency.

The root mean square value of the Error Vector Magnitude (EVM $\mathrm{RMS}_{\text {S }}$ [39] is a widely used figure-of-merit that evaluates the performance of the communication system. The lower the $\mathrm{EVM}_{\mathrm{RMS}}$ value, the higher the communication efficiency. The $\mathrm{EVM}_{\mathrm{RMS}}$ value obtained in each situation can be seen in Table I. The best result is obtained when $i_{O-D C}$ is $500 \mathrm{~mA}$ and $\Delta \mathrm{v}_{O}$ is 4.1 $\mathrm{V}$ (i.e., situation 1). If the lighting level is considerably reduced (i.e., the situation changes from 1 to 2 ), the $\mathrm{EVM}_{\mathrm{RMS}}$ rises dramatically although the communication signal power is the same. The reason is that the HB-LED string must be operating in the current-voltage linear region to properly reproduce the communication signal. However, $\Delta \mathrm{v}_{O}$ is too high for the $\mathrm{i}_{\mathrm{O}-\mathrm{DC}}$ value considered in situation 2 (Fig. 7 may help to understand this phenomena). Thus, the HB-LEDs operate close to the knee voltage, where the non-linear current-voltage relation causes high signal distortion. Then, the communication signal power should be reduced when considering the lighting level of situation 2 in order to avoid the non-linear region. Thus, $\mathrm{EVM}_{\mathrm{RMS}}$ can be improved by reducing $\Delta \mathrm{v}_{\mathrm{O}}$. This is equivalent to move from situation 2 to situation 4 . It can be seen that, as expected, $\mathrm{EVM}_{\mathrm{RMS}}$ is lower than in the case of situation 2 because it reduces the distortion caused by the non-linear operation. However, since the communication signal power is lower than in the case of situation $1, \mathrm{EVM}_{\mathrm{RMS}}$ is not as low as in that situation. Finally, $E_{\text {RMS }}$ can be reduced a bit by increasing the lighting level (i.e., moving from situation 4 to situation 3 ) in order to completely avoid the non-linear operation.

In conclusion, there is trade-off between power efficiency and communication efficiency. For a particular lighting level, the communication signal power must be the maximum possible without operating in the non-linear region for maximizing the communication efficiency. However, from the power efficiency perspective, the best results are obtained when minimizing the communication signal power.

\section{Feedback Loop Tests}

In order to check the dynamic behavior of the HB-LED driver, several tests have been carried out. Fig. 9(a) shows how the synchronous buck converter reduces its output voltage in order to compensate the fall of the HB-LEDs knee voltage with $\mathrm{T}_{\mathrm{J}}$. Thus, both $\mathrm{i}_{\mathrm{O}-\mathrm{DC}}$ and $\Delta \mathrm{i}_{\mathrm{O}}$ remain constant over time. For this test, the HB-LEDs heat sink was removed to see a considerable change during a short period of time.

Fig. 9(b) shows the results when two changes in the communication signal power are performed. When the increase

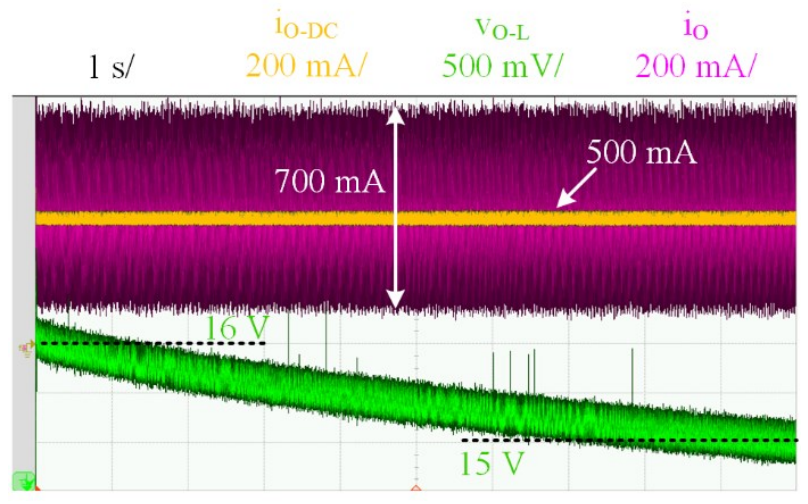

(a)

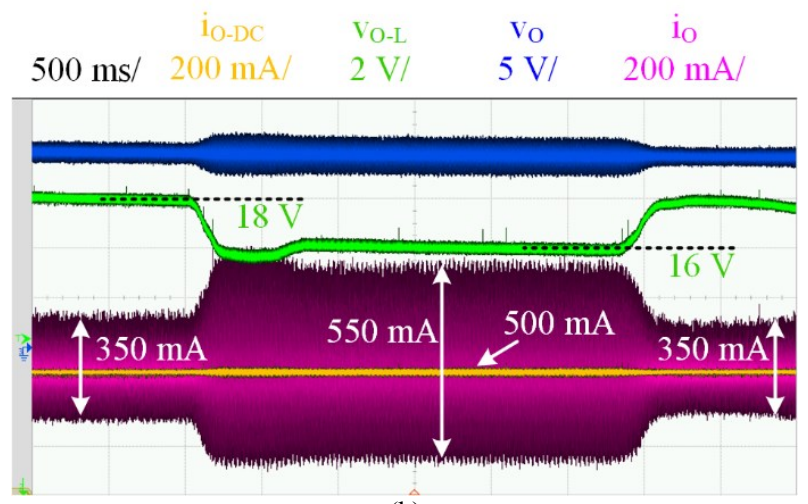

(b)

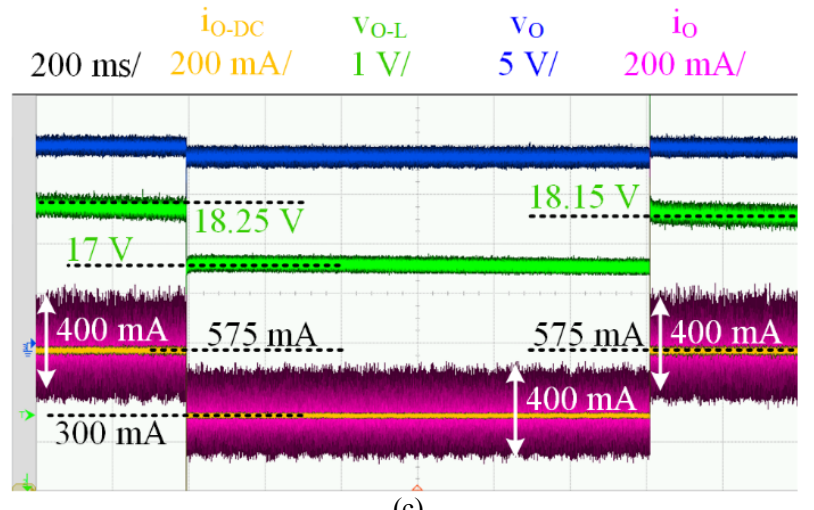

(c)

Fig. 9. Main experimental waveforms of the VLC system during the feedback loop tests: (a) Compensation of the knee voltage fall with $T_{\mathrm{J}}$. (b) Response to two changes of the communication signal power. (c) Response to two changes of the lighting level. 
of the communication signal power occurs, the multi-phase buck increases not only the AC component of its output voltage, but also the DC component. Remind that the DC component of the multi-phase buck converter output voltage is adjusted to provide the minimum value that enables the reproduction of the $\mathrm{AC}$ component. Thus, the synchronous buck converter reduces its output voltage to compensate the change.

Finally, Fig 9(c) shows the results when two changes in the lighting level are performed. It can be seen how the synchronous buck converter modifies its output voltage to track the desired lighting level.

\section{CONCLUSIONS}

Although VLC is an application with high potential for alleviating the congestion of the RF spectrum, it has some bottlenecks that are slowing down its deployment. One of the most important problems is the low power efficiency of the HBLED drivers proposed for reproducing advanced modulation schemes. The use of DC-DC converters seems to be the solution for solving the problem. However, the high bandwidth required for reproducing waveforms of several $\mathrm{MHz}$ causes that conventional HB-LED drivers for lighting applications cannot be directly adopted. The performance of a HB-LED driver made up of a multi-phase buck converter with high order output filter in output-series connection with a synchronous buck converter is deeply evaluated in this work. The multi-phase buck converter achieves high bandwidth operating in open-loop with high switching frequency. In this way, it is responsible for performing the small voltage variations (i.e., the part related to the communication signal). On the other hand, the synchronous buck converter is similar to conventional HB-LED drivers of lighting applications. It operates in close-loop ensuring that the desired lighting level is achieved. The split of the power enables the maximization of the power efficiency by minimizing the power that the multi-phase buck converter must deliver in each possible communication scenario. The wide experimental section allows to demonstrate the trade-off that exists between communication efficiency and power efficiency.

\section{ACKNOWLEDGMENT}

This work has been supported by the Spanish Government under the Project MINECO-17-DPI2016-75760-R, the scholarship FPU14/03268 and the Principality of Asturias under the Project FC-15- GRUPIN14-143, the Project SV-PA-17RIS3-4 and by European Regional Development Fund (ERDF) grants.

\section{REFERENCES}

[1] Cisco Systems, "Cisco Visual Networking Index: Global Mobile Data Traffic Forecast Update, 2016-2021”, Feb. 2017. [Online]. Available: http://www.cisco.com/c/en/us/solutions/collateral/serviceprovider/visual-networking-index-vni/mobile-white-paper-c11520862.html

[2] IEEE Standard for Local and Metropolitan Area Networks--Part 15.7: Short-Range Wireless Optical Communication Using Visible Light," in IEEE Std 802.15.7-2011, vol., no., pp.1-309, Sept. 62011

[3] GBI Research, Visible Light Communication (VLC) - A Potential Solution to the Global Wireless Spectrum Shortage, Sep. 2011 [Online]. Available: http://www.gbiresearch.com
[4] H. Elgala, R. Mesleh, and H. Haas, "Indoor optical wireless communication: Potential and state-of-the-art," IEEE Commun. Mag., vol. 49, no. 9, pp. 56-62, Sep. 2011.

[5] A. Jovicic, J. Li and T. Richardson, "Visible light communication: opportunities, challenges and the path to market," in IEEE Communications Magazine, vol. 51, no. 12, pp. 26-32, December 2013.

[6] J. Grubor, S. C. J. Lee, K. D. Langer, T. Koonen and J. W. Walewski, "Wireless high-speed data transmission with phosphorescent white-light LEDs," 33rd European Conference and Exhibition of Optical Communication - Post-Deadline Papers (published 2008), Berlin, Germany, 2007, pp. 1-2.

[7] H. Le Minh et al., "100-Mb/s NRZ visible light communications using a postequalized white LED," in IEEE Photonics Technology Letters, vol. 21, no. 15, pp. 1063-1065, Aug.1, 2009.

[8] H. Li, X. Chen, B. Huang, D. Tang and H. Chen, "High bandwidth visible light communications based on a post-equalization circuit," in IEEE Photonics Technology Letters, vol. 26, no. 2, pp. 119-122, Jan.15, 2014.

[9] S. Zhao, J. Xu and O. Trescases, "Burst-mode resonant LLC converter for an LED luminaire with integrated visible light communication for smart buildings," in IEEE Transactions on Power Electronics, vol. 29, no. 8, pp. 4392-4402, Aug. 2014.

[10] K. Modepalli and L. Parsa, "Dual-purpose offline LED driver for illumination and visible light communication," in IEEE Transactions on Industry Applications, vol. 51, no. 1, pp. 406-419, Jan.-Feb. 2015.

[11] J. Sebastián, D.G. Aller, J. Rodriguez, D.G. Lamar and P.F. Miaja, "On the role of the power electronics on visible light communication," 2017 IEEE Applied Power Electronics Conference and Exposition (APEC), Tampa, 2017.

[12] J. Rodriguez, D.G. Lamar, J. Sebastian and P.F. Miaja, “Taking advantage of the output voltage ripple of a two-phase buck converter to perform quadrature amplitude modulation for visible light communication," 2017 IEEE Applied Power Electronics Conference and Exposition (APEC), Tampa, 2017.

[13] J. Rodriguez, D.G. Lamar, J. Sebastian and P.F. Miaja, "Reproducing Single-Carrier Digital Modulation Schemes for VLC by Controlling the First Switching Harmonic of the DC-DC Power Converter Output Voltage Ripple," in IEEE Transactions on Power Electronics.

[14] F. Loose, R.R. Duarte, C.H. Barriquello, M.A. Dalla Costa, L. Teixeira, and A. Campos, "Ripple-based Visible Light Communication Technique for Switched LED Drivers," 2017 IEEE Industry Applications Society Annual Meeting, Cincinnati, OH, 2017.

[15] J. Rodriguez, D. G. Aller, D. G. Lamar, and J. Sebastian, " Energy Efficient Visible Light Communication Transmitter Based on the Split of the Power," 2017 IEEE Energy Conversion Congress and Exposition (ECCE), Cincinnati, OH, 2017.

[16] J. Armstrong and A. J. Lowery, "Power efficient optical OFDM," in Electronics Letters, vol. 42, no. 6, pp. 370-372, 16 March 2006.

[17] H. Elgala, R. Mesleh, H. Haas and B. Pricope, "OFDM Visible Light Wireless Communication Based on White LEDs," 2007 IEEE 65th Vehicular Technology Conference - VTC2007-Spring, Dublin, 2007, pp. 2185-2189.

[18] J. Armstrong, "OFDM for Optical Communications," in Journal of Lightwave Technology, vol. 27, no. 3, pp. 189-204, Feb.1, 2009.

[19] D. Tsonev et al., "A 3-Gb/s Single-LED OFDM-Based Wireless VLC Link Using a Gallium Nitride $\backslash \mathrm{mu}\{\mathrm{rm}$ LED $\}$," in IEEE Photonics Technology Letters, vol. 26, no. 7, pp. 637-640, April1, 2014.

[20] A. Keppens, W. R. Ryckaert, G. Deconinck, and P. Hanselaer, "High power light-emitting diode junction temperature determination from current-voltage characteristics," J. Appl. Phys., vol. 104, no. 9, pp. 093104-1-093104-8, Nov. 2008

[21] Osram Opto Semiconductors, "LED Fundamentals. Thermal Characteristics of LEDs", Aug. 2011. [Online]. Available: https://ledlight.osram-os.com/wp-content/uploads/2013/01/OSRAMOS LED-FUNDAMENTALS Thermal-Characteristics-ofLEDs v2 08-16-11 SCRIPT.p̄df

[22] On Semiconductor, "LED Lighting. Definitios and Characteristics", TND3228/D, Sep. 2007. [Online]. Available: https://www.onsemi.com/pub/Collateral/TND328-D.PDF 
[23] W. Chen, "High Efficiency, High Density, Polyphase Converters for High Current Applications," Linear Technology Corporation, Sept. 1999 [Online]. Available: http://www.linear.com/pc/downloadDocument.do? navId=H0,C1,C1003,C1042,C1032,C1062,P1726,D4166

[24] Xunwei Zhou, Pit-Leong Wong, Peng Xu, F. C. Lee and A. Q. Huang, "Investigation of candidate VRM topologies for future microprocessors," in IEEE Transactions on Power Electronics, vol. 15, no. 6, pp. 1172-1182, Nov 2000.

[25] Xunwei Zhou, Peng Xu and F. C. Lee, "A novel current-sharing control technique for low-voltage high-current voltage regulator module applications," in IEEE Transactions on Power Electronics, vol. 15, no. 6, pp. 1153-1162, Nov 2000.

[26] A. Soto, J. A. Oliver, J. A. Cobos, J. Cezon and F. Arevalo, "Power supply for a radio transmitter with modulated supply voltage," Applied Power Electronics Conference and Exposition, 2004. APEC '04. Nineteenth Annual IEEE, 2004, pp. 392-398 Vol.1.

[27] M. C. W. Hoyerby and M. E. Andersen, "High-Bandwidth, HighEfficiency Envelope Tracking Power Supply for 40W RF Power Amplifier Using Paralleled Bandpass Current Sources," 2005 IEEE 36th Power Electronics Specialists Conference, Recife, 2005, pp. 2804-2809.

[28] O. Garcia, A. de Castro, A. Soto, J. A. Oliver, J. A. Cobos and J. Cezon, "Digital control for power supply of a transmitter with variable reference," Twenty-First Annual IEEE Applied Power Electronics Conference and Exposition, 2006. APEC '06., Dallas, TX, 2006, pp. 6 pp.-

[29] P. Cheng, M. Vasić, O. García, J. Á. Oliver, P. Alou and J. A. Cobos, "Minimum Time Control for Multiphase Buck Converter: Analysis and Application," in IEEE Transactions on Power Electronics, vol. 29, no. 2, pp. 958-967, Feb. 2014.

[30] Y. Zhang, M. Rodríguez and D. Maksimović, "Output filter design in high-efficiency wide-bandwidth multi-phase buck envelope amplifiers," 2015 IEEE Applied Power Electronics Conference and Exposition (APEC), Charlotte, NC, 2015, pp. 2026-2032.

[31] M. Rodríguez, Y. Zhang and D. Maksimović, "High-Frequency PWM Buck Converters Using GaN-on-SiC HEMTs," in IEEE Transactions on Power Electronics, vol. 29, no. 5, pp. 2462-2473, May 2014.
[32] J. Sebastián, P. Fernández-Miaja, F. J. Ortega-González, M. Patiño and M. Rodríguez, "Design of a Two-Phase Buck Converter With FourthOrder Output Filter for Envelope Amplifiers of Limited Bandwidth," in IEEE Transactions on Power Electronics, vol. 29, no. 11, pp. 5933-5948, Nov. 2014.

[33] P. F. Miaja, A. Rodríguez and J. Sebastián, "Buck-Derived Converters Based on Gallium Nitride Devices for Envelope Tracking Applications," in IEEE Transactions on Power Electronics, vol. 30, no. 4, pp. 2084-2095, April 2015.

[34] Y. Zhang, J. Strydom, M. de Rooij and D. Maksimović, "Envelope tracking $\mathrm{GaN}$ power supply for $4 \mathrm{G}$ cell phone base stations," 2016 IEEE Applied Power Electronics Conference and Exposition (APEC), Long Beach, CA, 2016, pp. 2292-2297.

[35] A. Garcia i Tormo, A. Poveda, E. Alarcon and F. Guinjoan, "Designoriented characterisation of adaptive asynchronous $\Sigma \Delta$ modulation switching power amplifiers for bandlimited signals," 2009 IEEE International Symposium on Circuits and Systems, Taipei, 2009, pp. 2882-2885.

[36] M. C. W. Hoyerby and M. A. E. Andersen, "Ultrafast Tracking Power Supply With Fourth-Order Output Filter and Fixed-Frequency Hysteretic Control," in IEEE Transactions on Power Electronics, vol. 23, no. 5, pp. 2387-2398, Sept. 2008.

[37] J. Sebastián, P. Fernández-Miaja, A. Rodríguez and M. Rodríguez, "Analysis and Design of the Output Filter for Buck Envelope Amplifiers," in IEEE Transactions on Power Electronics, vol. 29, no. 1, pp. 213-233, Jan. 2014.

[38] P. F. Miaja, J. Sebastián, R. Marante and J. A. García, "A Linear Assisted Switching Envelope Amplifier for a UHF Polar Transmitter," in IEEE Transactions on Power Electronics, vol. 29, no. 4, pp. 1850-1861, April 2014.

[39] E. McCune, Practical digital wireless signals. Cambridge University Press, 2010. 